\title{
Uncertainty over fate of Mir experiments
}

[WASHINGTON] Russian and US engineers and scientists were this week taking stock of the damaged Mir space station to see whether power can be restored to its laboratory modules and what experiments - if any - can still be performed. The future of the 11-year-old craft, which has lasted far longer than any other Russian space station, hangs in the balance.

The Mir sustained serious damage last week when an unmanned cargo ship crashed into its Spektr laboratory module during a test of a new manual docking system. The crash damaged one of the station's powerproducing solar arrays and opened a small hole in the Spektr, which immediately began leaking its pressurized atmosphere.

That forced the two Mir cosmonauts and a US guest astronaut to disconnect power from three other arrays and seal the module off from the rest of the station. The equipment inside Spektr, roughly half of which was provided by the US space agency NASA, is now in a cold vacuum, and the experiments inside are thought to be lost.

But scientists working on the joint USRussian research programme will not know for certain until they take an inventory of the equipment that was inside Spektr when the accident occurred. Some is portable and may have been moved elsewhere on the station.

The 1,600 pounds of US-provided equipment inside Spektr includes a large freezer for storing blood samples, a centrifuge and equipment for cardiology investigations. The French national space agency, CNES, is also assessing the status of its equipment inside the module. Russian experiments in Spektr are concerned primarily with Earth observation and atmospheric studies.

Priroda, the laboratory module that contains US crystal growth experiments and other materials-science investigations, was not harmed. But these experiments require much power to run furnaces and other equipment. The now disconnected Spektr solar arrays provided about half the station's total electrical power. These would need to be reconnected to restore Mir's full research capabilities.

"The big unknown for [future] science [on Mir] is how the power shakes out," says Thomas Sullivan, a NASA scientist working on the joint research programme.

The current plan is for Mir's two cosmonauts to enter Spektr wearing spacesuits in mid-July and try to reconnect the power cables. The crew has never trained for such a job, and no one is sure if the repair is possible.

NASA officials and others were quick to point out that last week's accident had nothing to do with Mir's age. But the Russian space programme is clearly strained to breaking point. It also badly needs the revenue that comes from renting space on Mir.

France has signed a deal for a reported $\$ 40$ million to send an astronaut to the station in August, and again in 1999. Germany has also paid to use Mir, and the United States is spending \$472 million for seven long-term stays by NASA astronauts - two of which have yet to happen.

Last year, 25 per cent of the Russian Space Agency's funding came from renting out Mir, according to an analysis by ANSER Corporation of Washington DC. "Without that [revenue] it will be tough going," says Stephen Hopkins of ANSER.

Many US space officials worry that money spent patching up Mir will make it harder for Russia to meet its financial obligations to the international space station scheduled to begin construction next year.

Meanwhile, James Sensenbrenner (Republican, Wisconsin), chairman of the House Science Committee, has called on NASA administrator Daniel Goldin not to send another US astronaut to Mir until NASA can certify that the Russian station meets or exceeds US safety standards. Tony Reichhardt

\section{Australian science review defends diversity and overlaps}

[SYDNEY] Australia's chief scientist, John Stocker, who was asked by the government in February to carry out a review of the organization of Australian science, has recommended a largely uncontroversial streamlining of advisory mechanisms.

But in his report, published this week, Stocker argues against identifying "any gaps or overlaps", as he had been asked to do by the government. Gaps in research are "unavoidable" in a country the size of Australia, he says, while overlaps are "necessary and desirable".

The country's largest research agency, the Commonwealth Scientific and Industrial Research Organization (CSIRO), had been pushing to absorb the Australian Institute of Marine Science (AIMS) and possibly the Australian Nuclear Science and Technology Organization (ANSTO). AIMS is responsible for research in tropical waters, especially around the Great Barrier Reef and coral reefs off northwest Australia.

But Stocker comes down strongly in favour of diversity and plurality in publicly supported research, rejecting any concentration of research institutions within the portfolio of the Science and Technology Minister, Peter McGauran, who commissioned the review.

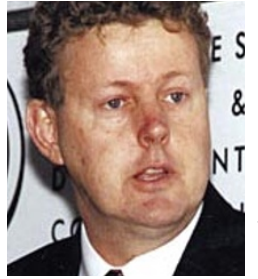

Stocker supports the $S$ efforts of the smaller agencies to retain their specialized identities, $N T$ and their claims that amalgamation would bring added costs and demands to hand over Reichtel: saw marine some of their resources. science prioritized. But he recommends that the three bodies should work out a common strategic plan.

Senior staff at AIMS are relieved that Stocker's proposals appear to reduce the threat to their independence. Russell Reichelt, director of AIMS, says he is "gratified" that marine science, which Stocker says is underfunded, is seen as a "high priority area".

Helen Garnett, executive director of ANSTO, argued in a statement that "the current pluralist system will continue to deliver best benefit". But CSIRO's chief executive, Malcolm McIntosh, repeated his organization's view that "it may be desirable for Australia to have fewer, larger and better-equipped institutions".

Stocker's report implicitly criticizes the cost-cutting strategy pursued by the Coalition government since last year's election. He says that incentives are necessary to boost business research and development, a view backed by numerous submissions. "My personal view is that it was not a good idea to reduce the tax break for industry from 150 to 125 per cent."

The main message of his report is that Australia urgently needs to develop policies for science and industry and to identify priorities if it is not to be left behind in the global technological market. He suggests that the Prime Minister's Science and Engineering Council, currently little more than a discussion group, should be given the authority to launch initiatives and to have their implementation overseen by a cabinet committee.

While declining to comment on whether the science minister should become a full member of the cabinet, Stocker argues that the minister's profile would be raised through membership of such a committee.

The impact of Stocker's proposals will depend on the reaction of the Prime Minister, John Howard, and on whether the cabinet is prepared to allow McGauran to take on a more powerful role. McGauran issued a statement saying that he needs to consult other ministers before the government issues a response. Peter Pockley 